\title{
Compounded Topical Amitriptyline for Neuropathic Pain: In Vitro Release from Compounding Bases and Potential Correlation with Clinical Efficacy
}

\author{
Ayah Shakshuki, Pollen Yeung, and Remigius U Agu
}

\begin{abstract}
Background: Topical amitriptyline has been described as having mixed clinical efficacy for neuropathic pain. A few case reports using higher concentrations of this compound found clinical benefit, but many of these studies did not describe the components used in formulating the amitriptyline preparations.

Objective: To generate reproducible clinical measures of the characteristics of amitriptyline diffusion from selected compounding bases, to support a scientific approach to base selection when compounding this drug for neuropathic pain.
\end{abstract}

Methods: Amitriptyline hydrochloride (1\%, 5\%, and 10\%) was compounded with 3 proprietary compounding bases: Lipoderm base, Emollient Cream, and Mediflo 30 pluronic lecithin organogel (PLO) gel. In vitro release of the drug from each base and subsequent permeation across artificial human skin were investigated with the Franz diffusion system. Amitriptyline release mechanisms were determined with kinetic models. How quickly and to what extent the drug leaves each base to diffuse through the skin were characterized by determining steady-state flux, cumulative permeation, and lag times.

Results: Release of amitriptyline was significantly higher from the Mediflo PLO gel than from the Lipoderm base or Emollient Cream $(p<0.05)$. Mean cumulative drug release after $24 \mathrm{~h}$, from the $10 \%$ formulation, was 23.9\% (standard deviation [SD] 4.1\%) for Lipoderm base, 41.8\% (SD $3.1 \%$ ) for Emollient Cream, and 53.2\% (SD 7.7\%) for Mediflo PLO gel. A high percentage of amitriptyline was retained in all 3 bases. Although amitriptyline release was highest with Mediflo PLO gel, this base resulted in significantly lower cumulative permeation relative to Lipoderm base and Emollient Cream $(p<0.05)$. There was a strong overall correlation between amitriptyline concentration, lag time, and flux. Higher concentrations were associated with significantly lower lag times and increased flux. The highest lag time and flux were observed for Mediflo PLO gel.

Conclusion: These data indicate that the therapeutic effectiveness of compounded amitriptyline for neuropathic pain depends on its diffusion out of the compounding bases and penetration through the skin.

\section{RÉSUMÉ}

Contexte : L'efficacité clinique de l'amitriptyline topique contre les douleurs neuropathiques a été décrite comme étant variable. Quelques rapports utilisant des concentrations plus élevées de cette base indiquent des avantages cliniques, mais bon nombre d'entre eux ne décrivent pas les composants des préparations d'amitriptyline.

Objectif : Établir des mesures cliniques reproductibles des caractéristiques de la diffusion de l'amitriptyline selon une approche scientifique de la sélection des bases pour la préparation de ce médicament contre les douleurs neuropathiques.

Méthodes : Le chlorohydrate d'amitriptyline (1\%, $5 \%$ et $10 \%)$ a été mélangé à trois bases de préparations magistrales brevetées : la base Lipoderm, la crème émolliente et le gel Mediflo PLO 30. La libération in vitro du médicament de chaque base et la perméation qui s'en est suivie dans la peau humaine artificielle ont été étudiées à l'aide du système de diffusion Franz. La définition des mécanismes de libération de l'amitriptyline repose sur des modèles cinétiques. La rapidité et la durée de libération du médicament de chaque base pour se diffuser dans la peau ont été caractérisées par la détermination du flux constant, de la perméation cumulée et des temps de latence.

Résultats : La libération de l'amitriptyline était sensiblement plus élevée quand le produit était mélangé au gel Mediflo PLO plutôt qu’à la base Lipoderm ou à la crème émolliente $(p<0,05)$. La libération cumulée du médicament, formule $10 \%$, après 24 h était de $23,9 \%$ (écart type [É.T.] $\pm 4,1 \%$ ) avec la base Lipoderm; 41,8 \% (É.T. $\pm 3,1 \%$ ) avec la crème émolliente et 53,2\% (É.T. \pm 7,7 \%) avec le gel Mediflo PLO. Les trois bases retenaient un pourcentage élevé d'amitriptyline. Bien que la libération d'amitriptyline était plus élevée en présence du gel Mediflo PLO, la perméation cumulée de cette base par rapport à celle de la base Lipoderm et de la crème émolliente était sensiblement moins élevée $(p<0,05)$. L'observation a révélé une forte corrélation générale entre la concentration d'amitriptyline, le temps de latence et le flux. Les concentrations plus élevées étaient associées à des temps de latence sensiblement moins élevés. C’est le gel Mediflo PLO qui a démontré une supériorité du temps de latence et du flux. 
Keywords: neuropathic pain, compounding, amitriptyline, compounding bases, transdermal drug absorption

Can J Hosp Pharm. 2020;73(2):133-40
Conclusion : Ces données indiquent que l'efficacité thérapeutique de la préparation d'amitriptyline contre les douleurs neuropathiques dépend de sa diffusion hors des bases dans les préparations magistrales et de sa pénétration dans la peau.

Mots-clés : douleurs neuropathiques, base, amitriptyline, bases pour préparations magistrales, absorption transdermique de médicaments

\section{INTRODUCTION}

A ccording to the International Association for the Study of Pain, neuropathic pain is "pain caused by a lesion or disease of the somatosensory nervous system". ${ }^{1}$ This means that the mechanisms leading to the pain involve the brain, spinal cord, and descending modulation systems. ${ }^{2}$ Amitriptyline produces analgesia in neuropathic pain by inhibiting voltage-gated sodium channels in the peripheral nerves. ${ }^{3}$ This mechanism is comparable to the effect of local anesthetics (e.g., lidocaine) that block sodium channels, leading to anesthesia, which is the rationale for their effectiveness as topical analgesics. ${ }^{4}$ Amitriptyline, a tricyclic antidepressant, is often used for neuropathic pain. ${ }^{5}$ It has a relatively high $\log \mathrm{P}$ value $^{6,7}$ and low molecular weight $(313.86 \mathrm{~g} / \mathrm{mol}),{ }^{8}$ important attributes that facilitate its permeation across the skin.

Topical application of a medication has the advantage of circumventing many adverse effects associated with oral formulations (e.g., dizziness, drowsiness, dry mouth, blurred vision, urinary retention, weight gain, and tachycardia). ${ }^{9}$ However, there is limited information on the stability of compounded products, release of the medication from compounding bases, and permeation across the skin. In the literature, evidence for efficacy is mixed, partly because of the relatively low amitriptyline concentrations in tested topical preparations. ${ }^{9}$ Lynch and others ${ }^{10}$ conducted a double-blind, randomized, placebo-controlled 3 -week study evaluating the efficacy of topical $2 \%$ amitriptyline, $1 \%$ ketamine, and a combination of the 2 medications. They found no significant difference in pain scores among the 3 groups and no systemic absorption. Other controlled trials using low concentrations ( $\leq 5 \%$ amitriptyline) had similar outcomes. ${ }^{11-13}$ Limited information exists regarding the types of bases used and the formulation/compounding methods. For studies involving higher drug concentrations, more consistent results have been obtained. For instance, according to case reports, patients experienced significant pain relief with amitriptyline concentrations ranging from $5 \%$ to $10 \% .{ }^{14-16}$ In their literature review, Kopsky and Hesselink ${ }^{14}$ found that among patients who received topical amitriptyline, $10 \%$ had a better pain response; however, one patient had trouble concentrating. More recently, a high concentration (10\%) of topical amitriptyline was reported to be effective for chemotherapy-induced peripheral neuropathy, which allowed chemotherapy to be administered at effective doses. ${ }^{17}$ However, a previously published systematic review found no evidence to support the use of low-dose amitriptyline (2\%) for this condition, ${ }^{18}$ an indication that strength of the formulation is important for topical use of amitriptyline in the management of chemotherapy-induced peripheral neuropathy.

Drug release from formulation excipients and subsequent permeation through the stratum corneum of the skin are highly dependent on physicochemical properties, drug concentration, and properties of the vehicle. ${ }^{19}$ Many studies that have examined the efficacy of topical amitriptyline alone either have used pluronic lecithin organogel (PLO) or have not identified the compounding bases. For those that used PLO, no rationale was given to justify this choice. ${ }^{20}$ Amitriptyline is a highly lipophilic, small-molecularweight compound, which means that the physicochemical characteristics of the compounding base must be considered when studying the rate and extent of amitriptyline release. The stability of the drug in the selected base and the absorption enhancement characteristics of that base are other important considerations.

The current study aimed to generate reproducible clinical measures of the characteristics of amitriptyline diffusion from selected compounding bases, to support a scientific approach to base selection when pharmacists are compounding the drug for topical application. To achieve this aim, we compared the in vitro release characteristics of amitriptyline compounded with 3 proprietary compounding bases: Lipoderm base, Emollient Cream, and Mediflo 30 PLO gel. The permeation of 1\%, 5\%, and $10 \%$ formulations across synthetic human skin was used to estimate skin permeation. The compounding bases were selected because of their popularity and frequency of use for compounding topical drugs in many pharmacies.

\section{MATERIALS AND METHODS}

\section{Materials}

Amitriptyline hydrochloride, Lipoderm base, and Emollient Cream were obtained from Professional Compounding Centers of America (Houston, Texas). Mediflo 30 PLO gel was purchased from Medisca Inc (Saint-Laurent, Quebec). Ethoxy diglycol was 
purchased from Galenova Inc (Saint-Hyacinthe, Quebec). Monobasic sodium phosphate monohydrate and phosphoric acid were obtained from Sigma-Aldrich (Oakville, Ontario), while analytical grade acetonitrile was from Fisher Scientific (New Jersey). Deionized water was processed using a Nanopure II filtering system (Barnstead Lab Water Products). Phosphatebuffered saline (PBS) 10x was bought from Sigma-Aldrich. Strat-M membrane was acquired from EMD Millipore (Billerica, Massachusetts). The coarse cellulose filter paper was purchased from Fisher Scientific (Ottawa, Ontario). Cellulose acetate membranes with a pore size of $0.47 \mu \mathrm{m}$ were obtained from Geotech Environmental Equipment Inc (Denver, Colorado). Tuffryn membrane filters with a pore size of $0.45 \mu \mathrm{m}$ were obtained from Pall Corporation (Ann Arbor, Michigan).

\section{Instrumentation}

Franz cells and a V-series stirrer were purchased from PermeGear, Inc (Hellertown, Pennsylvania). An Ecoline E100 heated water bath circulator (Lauda-Brinkmann, Lauda-Koenigshofen, Germany) was used to maintain the cells at a specific temperature. A Varian-920 liquid chromatograph with a quaternary gradient pump, autosampler with $50-\mu \mathrm{L}$ sample loop, an ultraviolet-visible detector, and Galaxie chromatographic software (Varian Inc, Walnut Creek, California) was used for sample analysis. Chromatographic separation was performed with a $\mu$ Bondapack $125 \AA(3.9 \mathrm{~mm} \times 300 \mathrm{~mm} ; 10 \mu \mathrm{m}) \mathrm{C} 18$ column (Waters Corporation, Milford, Massachusetts).

\section{Quantification of Amitriptyline}

Spectrophotometric methods for amitriptyline are complicated and result in low sensitivity. ${ }^{21-23}$ Therefore, the United States Pharmacopoeia (USP) high-performance liquid chromatography method was used. ${ }^{24}$ The mobile phase was prepared by combining phosphate buffer and acetonitrile in a 58:42 ratio v/v, vacuumfiltering through a $0.22-\mu \mathrm{m}$ nylon filter, and degassing for $20 \mathrm{~min}$. The chromatographic method was previously validated for specificity, linearity, range, accuracy, precision, limit of detection, and limit of quantification, in accordance with the International Conference on Harmonization guidelines. ${ }^{25}$

\section{Preparation of Compounded Amitriptyline}

Amitriptyline $\mathrm{HCl}$ was compounded with Lipoderm base, Emollient Cream, and Mediflo 30 PLO gel. Three different concentrations (1\%,5\%, and $10 \%)$ were made with each base. To prepare the formulations, an appropriate amount of amitriptyline was weighed and triturated to produce a fine powder using mortar and pestle. The required amount of ethoxy diglycol was added to the fine powder and levitated to produce a smooth paste. Each base was added to the prepared paste using the principles of geometric dilution. The cream was transferred to a jar, mixed using an Unguator electronic mortar and pestle (Gako, Norman, Oklahoma), and processed once through an Exakt 50 ointment mill (Exakt Technologies Inc, Oklahoma City, Oklahoma). The resulting amitriptyline formulations in Lipoderm base, Emollient Cream, and Mediflo 30 PLO gel were placed in Ecolo-Jar ointment jars (EcoloPharm, Chambly, Quebec).

\section{In Vitro Drug Release and Permeation Studies}

To characterize the release rate of amitriptyline from the various topical formulations, the in vitro Franz diffusion cell system was used (diffusion area $0.64 \mathrm{~cm}^{2}$ and receptor medium capacity $5 \mathrm{~mL}$ ). The system was maintained at a constant temperature of $32 \pm 0.5^{\circ} \mathrm{C}$ with the heated water bath circulator. A 5-mL volume of PBS ( $\mathrm{pH} 7.4$ ) was added slowly from a pipette to each Franz cell through the receptor chamber orifice. Small magnetic stir bars were placed into the receptor chambers of each cell, and the system was equilibrated for a minimum of $60 \mathrm{~min}$.

To investigate amitriptyline release, cellulose membranes were soaked in PBS for 30 min. Each wetted membrane was placed on top of one receptor chamber with the Teflon O-ring and donor chamber placed over the membrane and secured with a metal clamp. Each compounded amitriptyline formulation (100 $\pm 0.5 \mathrm{mg}$ ) was applied on the membrane with a glass rod. The mass of the glass rod was recorded before and after each application to determine the exact quantity applied. One cell, containing the base with ethoxy diglycol only, was reserved as a blank. Both the sampling port opening and the donor chamber chimney were covered with Parafilm. Samples $(0.5 \mathrm{~mL})$ were drawn at $0.5,1,2,3,4,6,8,12$, and $24 \mathrm{~h}$. The volume of receptor medium taken during each sampling was replaced with fresh PBS. Cumulative drug release was calculated using a standard equation ${ }^{26}$ :

$$
Q=\left(\mathrm{C}_{\mathrm{n}} \mathrm{V}+\sum_{i=1}^{n-1} \mathrm{CiS}\right)
$$

where $\mathrm{C}_{n}$ is the concentration of drug determined at the $n$th sampling interval, $\mathrm{V}$ is the volume of the Franz diffusion cell, $\sum_{i=1}^{n-1} C i$ is the sum of concentrations of drug determined at sampling intervals 1 through $n-1$, and $S$ is the surface area of the sample membrane.

To determine the mechanism of drug release from each of the formulations, the data were analyzed with the first-order, second-order, Higuchi, Korsmeyer-Peppas, and Hixon-Crowell kinetic models.

Amitriptyline permeation studies were conducted identically to the drug release studies except a different membrane was used and neither the receptor nor the sampling port was covered during the experiments. Strat-M membrane, which is an in vitro membrane model that functionally simulates drug permeation through human skin, was placed on the receptor. Each topical formulation was tested in triplicate, and flux and lag times were calculated. The steady-state flux was the slope divided by the diffusional area from the linear portion of the cumulative drug 
permeation graph, whereas lag time was the $x$-intercept. Additionally, after the permeation experiments were completed, the Strat-M membrane and the diffusion cell were rinsed with deionized water, which was then used to determine overall drug recovery.

\section{Statistical Analysis}

Differences between mean cumulative amitriptyline release or permeation at each time point were determined using 2-way statistical analysis of variance with Tukey multiple-comparison post hoc tests using GraphPad Prism software version 7.0 (GraphPad Software Inc, San Diego, California) with 95\% confidence intervals.

\section{RESULTS}

\section{In Vitro Amitriptyline Release from Compounding Bases}

Cumulative release of amitriptyline from the $10 \%$ formulation in each of the 3 bases is shown in Figure 1A. There was no significant difference in amitriptyline release from Lipoderm base and Emollient Cream in the first $4 \mathrm{~h}(p<0.05)$. However, after $4 \mathrm{~h}$, significantly more amitriptyline was released from the Emollient Cream than from the Lipoderm base $(p<0.05)$. At all time points after $3 \mathrm{~h}$, release of drug from Mediflo PLO gel was significantly higher than release from the other 2 bases $(p<0.05)$. Mean cumulative drug release after $24 \mathrm{~h}$ was $23.9 \%$ (standard deviation [SD] 4.1\%) for Lipoderm base, 41.8\% (SD 3.1\%) for Emollient Cream, and 53.2\% (SD 7.7\%) for Mediflo PLO gel. A high percentage of amitriptyline was retained in all 3 bases.

Cumulative release of amitriptyline from the $5 \%$ formulation in each of the 3 bases (Figure 1B) followed a similar pattern, except that no significant difference was observed between Mediflo PLO gel and Emollient Cream beyond 6 h $(p>0.05)$. However, there was no difference among the 3 bases in the first $2 \mathrm{~h}(p>0.05)$. As for the $10 \%$ formulation, there was significantly less amitriptyline release from the Lipoderm base at all time points after $4 \mathrm{~h}(p<0.05)$. Mean cumulative drug release after $24 \mathrm{~h}$ was 23.6\% (SD 4.1\%) for Lipoderm base, 40.8\% (SD 3.1\%) for Emollient Cream, and 39.7\% (SD 2.8\%) for Mediflo PLO gel. Figure $1 \mathrm{C}$ shows significant differences in cumulative amitriptyline release from the $1 \%$ formulation in all 3 bases. After $2 \mathrm{~h}$, more amitriptyline was released from Mediflo PLO gel than from the other 2 bases $(p<0.05)$. Also, significantly more drug was released from the Emollient Cream than from the Lipoderm base $(p<0.05)$. Mean drug release after $24 \mathrm{~h}$ was $35.5 \%$ (SD 4.6\%) for Emollient Cream and 64.0\% (SD 13.8\%) for Mediflo PLO gel; release from Lipoderm base was much lower, at about $10 \%$. Consistently less amitriptyline was released from Lipoderm base than from any other base, regardless of drug concentration.

The fact that a significant amount of drug was retained in all 3 bases compelled us to explore potential amitriptyline release
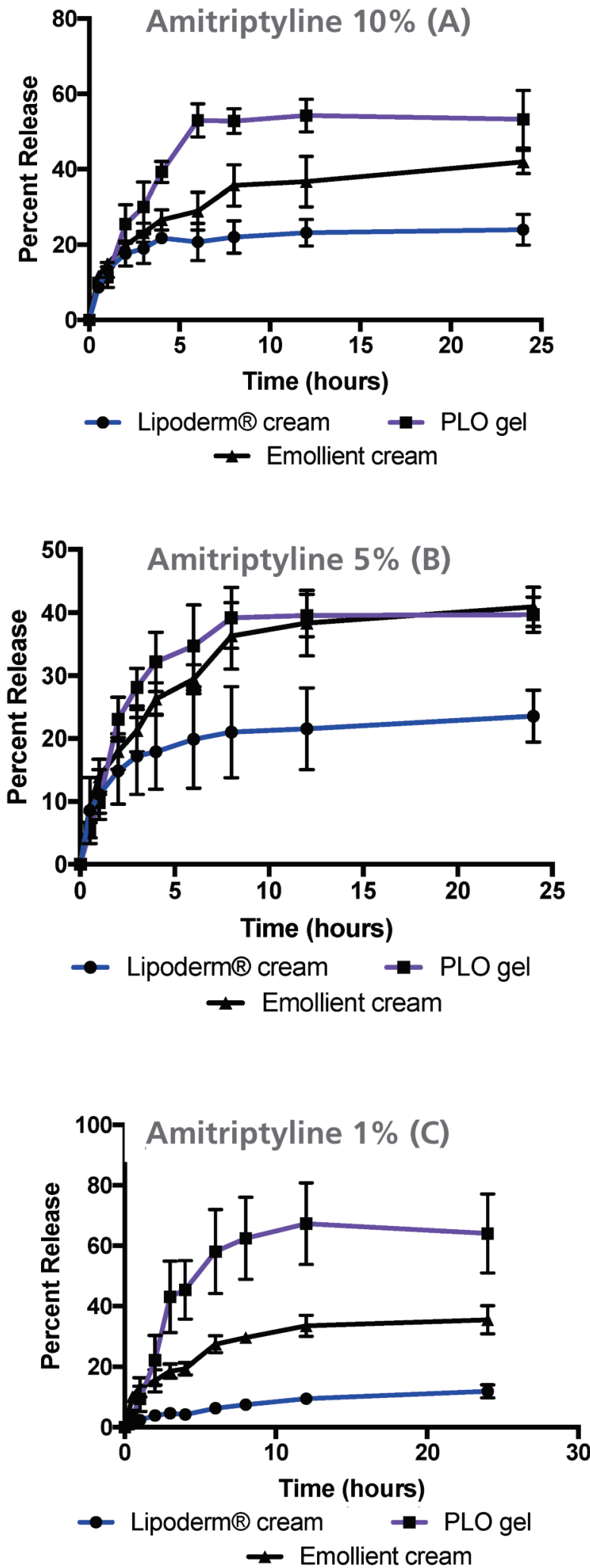

Figure 1. Cumulative release of amitriptyline from each of the 3 bases. (A) 10\% formulation of amitriptyline; (B) $5 \%$ formulation of amitriptyline; (C) $1 \%$ formulation of amitriptyline. 
mechanisms (Table 1). The $R^{2}$ values for amitriptyline compounded with Lipoderm base, Emollient Cream, and Mediflo PLO gel were highest with the Higuchi model, which implies that the drug was released from the bases according to this model. However, the $R^{2}$ values for the Korsmeyer-Peppas model were also relatively high, which suggests drug release by multiple mechanisms. The slope of the linear regression equations for the Korsmeyer-Peppas model was used to confirm whether other release mechanisms contributed to amitriptyline release from the bases. All slopes for release of amitriptyline (1\%, 5\%, and 10\% formulations) from Lipoderm base and Mediflo PLO gel were between 0.5 and 1 , which suggests anomalous release. However, release of amitriptyline (1\%, 5\%, and 10\% formulations) from Emollient Cream had slopes below 0.5, which implies release by Fickian diffusion.

\section{In Vitro Amitriptyline Permeation across Simulated Skin}

Permeation of $10 \%$ amitriptyline through Strat-M membrane varied with the base used (Figure 2A). Although the highest amitriptyline release occurred with Mediflo PLO gel, this base resulted in significantly lower cumulative permeation at all time points relative to Lipoderm base and Emollient Cream $(p<0.05)$.

The cumulative permeation of 5\% amitriptyline through Strat-M synthetic skin is illustrated in Figure 2B. At this concentration, no significant difference in permeation was observed between Lipoderm base and Emollient Cream $(p>0.05)$. Surprisingly, when the amitriptyline concentration in Mediflo PLO gel was reduced from $10 \%$ to $5 \%$, no drug permeation occurred. Decreased and erratic permeation was observed when amitriptyline concentration was reduced from $5 \%$ to $1 \%$. For the most part, there was no permeation, although in some instances unreliable, up-and-down, nonpredictable permeation occurred (Figure 2C). For instance, the mean 4-h permeation of amitriptyline $1 \%$ was $0.43 \%$ (SD $0.04 \%$ ) in Lipoderm base and $0.37 \%$
(SD 0.24\%) in Emollient Cream, with no further permeation beyond that time point.

The total quantity of amitriptyline that permeated the membrane over $24 \mathrm{~h}$ (expressed as a percentage relative to the amount applied) is summarized in Figure 3. At 10\% amitriptyline, mean permeation through Strat-M membrane was $16.8 \%$ (SD 0.9\%) for Lipoderm base, 15.4\% (SD 1.5\%) for Emollient Cream, and 9.3\% (SD 1.5\%) for Mediflo PLO gel. Significantly lower permeation occurred with Mediflo PLO gel $(p<0.05)$, but no difference was observed between Lipoderm base and Emollient Cream $(p>0.05)$. At $5 \%$ amitriptyline, mean permeation was $10.9 \%$ (SD 0.9\%) for Lipoderm base, 9.7\% (SD 0.5\%) for Emollient Cream, and 0\% for Mediflo PLO gel. Significantly less permeation occurred with Mediflo PLO gel $(p<0.05)$, but no difference between Lipoderm base and Emollient Cream $(p>$ $0.05)$ was observed. Decreasing the amitriptyline strength from $10 \%$ to $5 \%$, and further from $5 \%$ to $1 \%$, resulted in significant differences in the total percent permeation $(p<0.05)$. Total amitriptyline recovery from Strat-M membrane, the receptor medium, and equipment was within acceptable limits (90\%-110\%).

Lag time refers to the time needed for a drug to start passing through the skin, which may signify its onset of action. At 5\% and $10 \%$ strengths, amitriptyline compounded with Lipoderm base permeated the skin rapidly, with the flux of $10 \%$ strength almost double that of the $5 \%$ preparation (Table 2). For amitriptyline in Emollient Cream, permeation began after about $45 \mathrm{~min}$ for the $5 \%$ formulation and after about $7 \mathrm{~min}$ for the $10 \%$ formulation. There was a strong overall correlation among amitriptyline concentration, lag time, and flux. Higher concentrations were associated with significantly reduced lag times and increased flux. The highest lag time and flux were observed for Mediflo PLO gel.

\section{DISCUSSION}

In vitro drug release testing and the subsequent investigation of active ingredient permeation through the skin from semisolid

Table 1. Modelling of Mean Amitriptyline Release

\begin{tabular}{|c|c|c|c|c|c|}
\hline \multirow[b]{2}{*}{$\%$ Amitriptyline in Vehicle } & \multicolumn{5}{|c|}{ Model; $R^{2}$ Value } \\
\hline & Higuchi & First-Order & Second-Order & Hixon-Crowell & Korsmeyer-Peppas \\
\hline \multicolumn{6}{|l|}{ Lipoderm base } \\
\hline $10 \%$ & 0.9801 & 0.4059 & 0.4319 & 0.4232 & 0.8302 \\
\hline $5 \%$ & 0.9621 & 0.5404 & 0.5369 & 0.5260 & 0.8168 \\
\hline $1 \%$ & 0.9809 & 0.856 & 0.8687 & 0.8645 & 0.7179 \\
\hline \multicolumn{6}{|l|}{ Emollient Cream } \\
\hline $10 \%$ & 0.9843 & 0.6709 & 0.7371 & 0.7155 & 0.9521 \\
\hline $5 \%$ & 0.9944 & 0.6616 & 0.7141 & 0.6974 & 0.9558 \\
\hline $1 \%$ & 0.9771 & 0.6793 & 0.7252 & 0.7104 & 0.8732 \\
\hline \multicolumn{6}{|l|}{ Mediflo 30 PLO gel } \\
\hline $10 \%$ & 0.9745 & 0.4724 & 0.5136 & 0.5005 & 0.7939 \\
\hline $5 \%$ & 0.9452 & 0.4961 & 0.5337 & 0.5212 & 0.824 \\
\hline $1 \%$ & 0.9819 & 0.543 & 0.6015 & 0.3441 & 0.844 \\
\hline
\end{tabular}



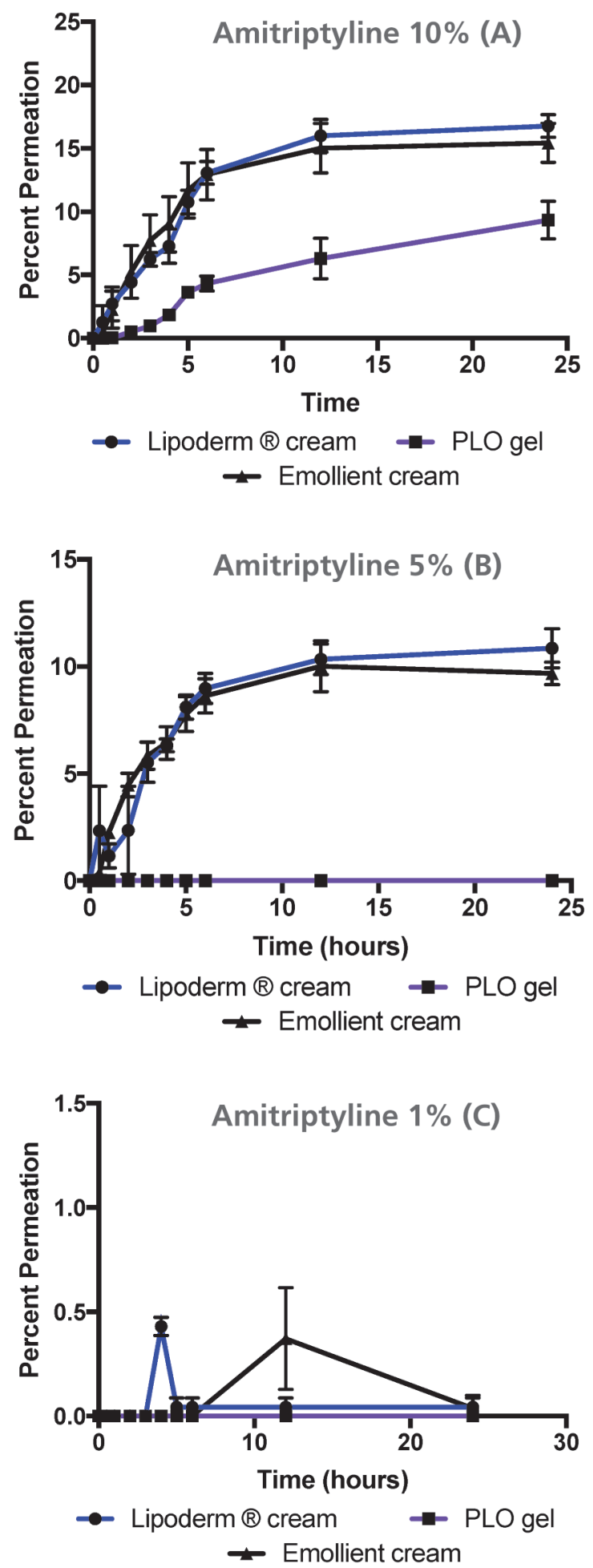

Figure 2. Permeation of amitriptyline through Strat-M membrane. (A) 10\% formulation of amitriptyline; (B) 5\% formulation of amitriptyline; (C) $1 \%$ formulation of amitriptyline.

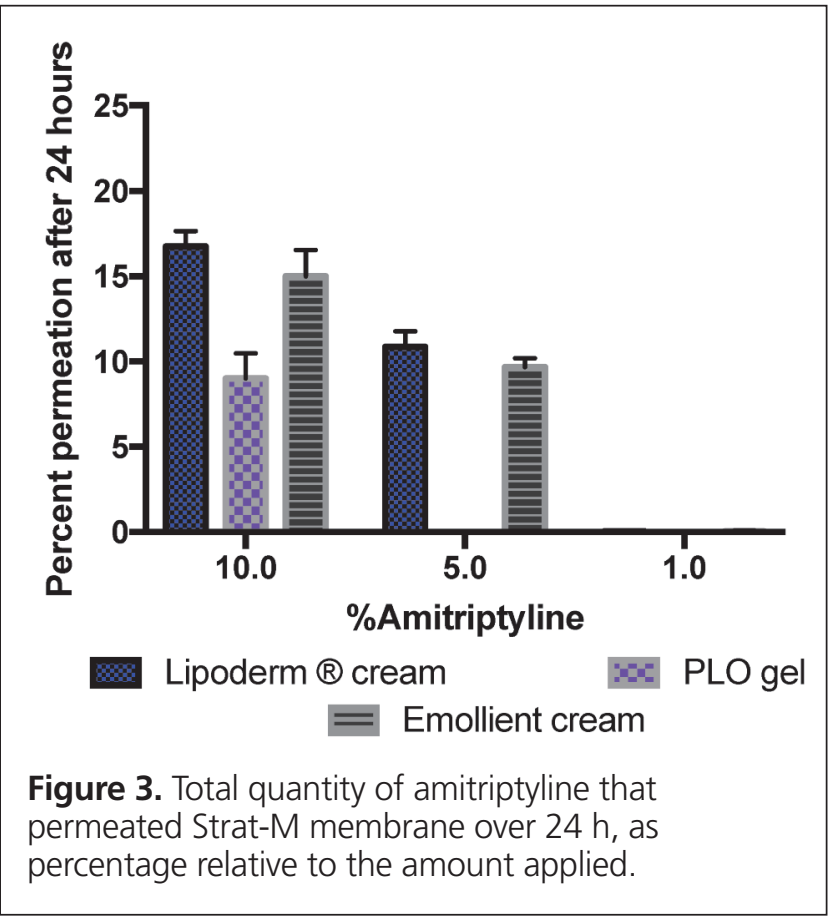

Table 2. Lag Times and Flux of Amitriptyline Permeation Through Strat-M Synthetic Human Skin

\begin{tabular}{lcc} 
\% Amitriptyline in Vehicle & $\begin{array}{c}\text { Lag Time } \\
(\mathrm{min})\end{array}$ & $\begin{array}{c}\text { Flux } \\
\left(\mathrm{mg} / \mathrm{h} \text { per } \mathrm{cm}^{2}\right)\end{array}$ \\
\hline Lipoderm base & & \\
$10 \%$ & 0 & 0.2601 \\
$5 \%$ & 0 & 0.1458 \\
\hline Emollient Cream & 6.8 & 0.3878 \\
$10 \%$ & 46.3 & 0.1459 \\
$5 \%$ & & \\
\hline Mediflo 30 PLO gel & 47.6 & 0.0913 \\
\hline $10 \%$ & &
\end{tabular}

preparations are essential in formulation development, quality control procedures, and prediction of in vivo performance of a product. ${ }^{27}$

In addition to aiding in formulation development, in vitro drug release testing serves to compare the performance of different noncommercial compounded medications with various bases and excipients. ${ }^{26}$ According to the USP, "The vertical diffusion cell (VDC) system is a simple, reliable, and reproducible means of measuring drug release from semisolid dosage forms". ${ }^{28}$ In this system, topical formulations are placed on a membrane support in the donor chamber, and the released drug diffuses to the acceptor chamber, from where samples are collected at specific intervals for analysis with a suitable analytical method.

The selection and composition of the vehicle play a critical role in drug release and permeation behaviour, which ultimately hinders or enhances clinical response. ${ }^{26}$

In this study, the compounding of amitriptyline with various bases was investigated for release of the drug from the compound- 
ing bases and subsequent permeation across Strat-M, a synthetic membrane that mimics the morphology of human skin. ${ }^{29,30}$ The Strat-M product was selected for this study because of its high in vitro - in vivo correlation for a variety of active pharmaceutical ingredients. It also offers lower sample variability than human skin. ${ }^{29-31}$

Several patient case reports and controlled trials have used topical amitriptyline for treating peripheral neuropathic pain. However, there is a surprising absence of vehicle description, as well as release and permeation data. In trials that did show evidence for efficacy, higher concentrations (> 5\%) were used, whereas studies that used lower strengths and cases in which the compounding bases were described as "PLO" resulted in no benefits. ${ }^{14-16}$ Our data may shed some light on these reported observations. The release of amitriptyline from all formulations most closely followed the Higuchi kinetic model, which suggests that its release was controlled mainly by its rate of diffusion from the upper areas of the vehicles toward the surface exposed to the membrane. ${ }^{32}$ However, relatively high $R^{2}$ values were calculated with the Korsmeyer-Peppas model, which implies the possible involvement of other release mechanisms. ${ }^{33}$ Amitriptyline release from Emollient Cream (1\%, 5\%, and 10\% formulations) had slopes under 0.5 , implying release by Fickian diffusion. All of the slopes for amitriptyline release from Lipoderm base and Mediflo PLO gel (1\%, 5\%, and 10\% formulations) were between 0.5 and 1. The mechanism, in this case, follows non-Fickian or anomalous transport, meaning that vehicle swelling and/or erosion contributed to drug release. ${ }^{33}$

Despite these potential mechanisms of amitriptyline release, we found that amitriptyline compounded with Mediflo PLO gel at $1 \%$ and $5 \%$ strengths did not permeate through the artificial skin membrane. The result was similar with the $1 \%$ formulation in Emollient Cream and Lipoderm base, where a minimal quantity of the drug was detected at the 12- and 4-h time points, respectively. Low lag time and high flux are important characteristics of topical analgesics because, with typical patient use, the topical formulation may be rubbed or washed off in a short period. As shown in Table 2, amitriptyline 5\% in Lipoderm base had high flux, whereas amitriptyline 10\% in Emollient Cream had low lag time. The lack of clinical efficacy in formulations containing less than 5\% amitriptyline makes sense given poor permeation at that concentration. Overall, amitriptyline $5 \%$ or $10 \%$ compounded in Lipoderm base or Emollient Cream resulted in the highest drug permeation and low lag times.

On the basis of our data, it was evident that substantial amounts of amitriptyline remained in the bases and were unavailable for diffusion across the skin. Ironically, the vehicle that resulted in the highest overall amitriptyline release (Mediflo PLO gel) had the highest lag time and the least permeation over a 24-h period. Theoretically, for this base, more amitriptyline was available to permeate through the skin, ${ }^{34}$ but its comparatively lower flux suggests that drug release and permeation should be optimized for individual drugs before choosing a particular base for compounding specific drugs for patient use. The in vitro data generated through the permeation experiments with the Strat-M membrane reflects the most absorption that could potentially occur, given that in vitro methods tend to overestimate in vivo absorption in human subjects. ${ }^{35}$ For instance, topically applied drugs are often rubbed or washed off after a relatively short period, which was not the case during the in vitro permeation studies.

\section{CONCLUSION}

Our in vitro drug release and permeation data for amitriptyline revealed that roughly half of the active drug was retained in all 3 formulations after $24 \mathrm{~h}$. This ultimately affected drug permeation in compounded formulations with less than $5 \%$ amitriptyline. These data indicate that the ability of amitriptyline to diffuse from various compounding bases and the absorptionenhancing properties of these bases are essential in ensuring optimal drug release, permeation through the skin, and perhaps therapeutic effectiveness. Pharmacists should, therefore, ask the suppliers of compounding bases to provide drug release and possibly permeation data that justify the use of a specific base for compounding topical pain medications.

\section{References}

1. Neuropathic pain [definition]. In: IASP terminology: pain terms. International Association for the Study of Pain; [updated 2017 Dec 14; cited 2020 Feb 17]. Available from: https://www.iasp-pain.org/terminology?navItem Number=576\#Neuropathicpain

2. Cohen SP, Mao J. Neuropathic pain: mechanisms and their clinical implications [erratum in BMJ. 2014;348:g2323]. BMJ. 2014;348: f7656.

3. Gerner P, Wang GK. Mechanisms of tricyclic antidepressants in pain modulation. In: Mao J, editor. Comparing preclinical studies and clinical pain management: lost in translation? Nova Science Publishers; 2006:189-206.

4. Sudoh Y, Cahoon EE, Gerner P, Wang GK. Tricyclic antidepressants as long-acting local anesthetics. Pain. 2003;103(1-2):49-55.

5. Moulin D, Boulanger A, Clark AJ, Clarke H, Dao T, Finley GA, et al.; Canadian Pain Society. Pharmacological management of chronic neuropathic pain: revised consensus statement from the Canadian Pain Society. Pain Res Manag. 2014;19(6):328-35.

6. Williams DA. Antidepressants. In: Lemke TL, Williams DA, Roche VF, Zito SW, editors. Foye's principles of medicinal chemistry. Lippincott Williams \& Wilkins; 2012:547-600.

7. Gillman PK. Tricyclic antidepressant pharmacology and therapeutic drug interactions updated. Br J Pharmacol. 2007;151(6):737-48.

8. Manzo RH, Olivera ME, Amidon GL, Shah VP, Dressman JB, Barends DM. Biowaiver monographs for immediate release solid oral dosage forms: amitriptyline hydrochloride. J Pharm Sci. 2006;95(5):966-73.

9. Elavil (amitriptyline hydrochloride tablets USP) [monograph]. A A Pharma Inc; 2010 [cited 2019 July 7]. Available from: https://www.aapharma.ca/ downloads/en/PIL/ELAVIL_PM.pdf

10. Lynch ME, Clark AJ, Sawynok J, Sullivan MJ. Topical $2 \%$ amitriptyline and $1 \%$ ketamine in neuropathic pain syndromes: a randomized, double-blind, placebo-controlled trial. Anesthesiology. 2005;103(1):140-6.

11. Ho KY, Huh BK, White WD, Yeh CC, Miller EJ. Topical amitriptyline versus lidocaine in the treatment of neuropathic pain. Clin J Pain. 2008; 24(1):51-5.

12. Gewandter JS, Mohile SG, Heckler CE, Ryan JL, Kirshner JJ, Flynn PJ, et al. A phase III randomized, placebo-controlled study of topical amitriptyline and ketamine for chemotherapy-induced peripheral neuropathy (CIPN): a University of Rochester CCOP study of 462 cancer survivors. Support Care Cancer. 2014;22(7):1807-14 
13. Barton DL, Wos EJ, Qin R, Mattar BI, Green NB, Lanier KS, et al. A double-blind, placebo-controlled trial of a topical treatment for chemotherapyinduced peripheral neuropathy: NCCTG trial N06CA. Support Care Cancer. 2011;19(6):833-41.

14. Kopsky DJ, Hesselink JM. High doses of topical amitriptyline in neuropathic pain: two cases and literature review. Pain Pract. 2012;12(2):148-53.

15. Kopsky DJ, Liebregts R, Keppel Hesselink JM. Central neuropathic pain in a patient with multiple sclerosis treated successfully with topical amitriptyline. Case Rep Med. 2012;2012:471835.

16. Liebregts R, Kopsky DJ, Hesselink JM. Topical amitriptyline in posttraumatic neuropathic pain. J Pain Symptom Manage. 2011;41(4): e6-7.

17. Yang XD, Fang PF, Xiang DX, Yang YY. Topical treatments for diabetic neuropathic pain. Exp Ther Med. 2019;17(3):1963-76.

18. Thompson DF, Brooks KG. Systematic review of topical amitriptyline for the treatment of neuropathic pain. J Clin Pharm Ther. 2015;40(5):496-503.

19. Kriwet K, Miiller-Goymann CC. Diclofenac release from phospholipid drug systems and permeation through excised human stratum corneum. Int $J$ Pharm. 1995;120(5):231-42.

20. Hesselink JMK. Topical analgesics: critical issues related to formulation and concentration. J Pain Relief. 2016;5(6):1000274.

21. Deepakumari HN, Prashanth MK, Revanasiddappa HD. Validated and sensitive spectrophotometric method for the determination of amitriptyline hydrochloride. Chem Sci J. 2013;4(2):072.

22. Starczewska B, Jasińska A. Analytical application of the reactions of amitriptyline with eriochrome cyanine $\mathrm{R}$ and pyrocatechol violet. Acta Pol Pharm. 2003;60(6):417-23.

23. García Fraga JM, Jiménez Abizanda AI, Jiménez Moreno F, Arias León JJ. Simultaneous determination of imipramine and amitriptyline by derivative spectrophotometry. J Pharm Biomed Anal. 1991;9(2):109-15.

24. Amitriptyline. In: USP 29-NF24. United States Pharmacopeial Convention; 2007 [cited 2018 Sep 14]. p. 148. Available from: http://ftp.uspbpep.com/ v29240/usp29nf24s0_m3480.html

25. ICH Topic Q2 (R1): Validation of analytical procedures: text and methodology. CPMP/ICH/381/95. European Medicines Agency; 1995 Jun [cited 2020 Apr 7]. Available from: https://www.ema.europa.eu/en/documents/ scientific-guideline/ich-q-2-r1-validation-analytical-procedures-textmethodology-step-5_en.pdf

26. Thakker $\mathrm{KD}$, Chern $\mathrm{WH}$. Development and validation of in vitro release tests for semisolid dosage forms-case study. Dissolut Technol. 2003;10:10-5.

27. Goebel K, Sato MEO, de Souza DF, Murakami FS, Andreazza IF. In vitro release of diclofenac diethylamine from gels: evaluation of generic semisolid drug products in Brazil. Braz J Pharm Sci. 2013;49:211-9.

28. Ueda CT, Shah VP, Derdzinski K, Ewing G, Flynn G, Maibach H, et al. Topical and transdermal drug products. Pharmacop Forum. 2009; 35(4):750-64
29. Simon A, Amaro MI, Healy AM, Cabral LM, de Sousa VP. Comparative evaluation of rivastigmine permeation from a transdermal system in the Franz cell using synthetic membranes and pig ear skin with in vivo-in vitro correlation. Int J Pharm. 2016;512(1):234-41.

30. Joshi V, Brewster D, Colonero P. In vitro diffusion studies in transdermal research: a synthetic membrane model in place of human skin. Drug Dev Deliv. 2012;12(2):40-2.

31. Uchida T, Kadhum WR, Kanai S, Todo H, Oshizaka T, Sugibayashi K. Prediction of skin permeation by chemical compounds using the artificial membrane, Strat-M ${ }^{\mathrm{TM}}$. Eur J Pharm Sci. 2015;67:113-8.

32. Christensen JM, Chuong MC, Le H, Pham L, Bendas E. Hydrocortisone diffusion through synthetic membrane, mouse skin, and epiderm ${ }^{\mathrm{TM}}$ cultured skin. Arch Drug Inf. 2011;4(1):10-21.

33. Nisha GS, Sharol R, Charyulu RN, Rahul V. Design, development and evaluation of antiviral drug loaded microcapsules prepared by microencapsulation technique. Res J Pharm Biol Chem Sci. 2013;4(3):585-95.

34. Shipton EA. Skin matters: identifying pain mechanisms and predicting treatment outcomes. Neurol Res Int. 2013;2013:329364.

35. Lehman PA, Raney SG, Franz TJ. Percutaneous absorption in man: in vitro-in vivo correlation. Skin Pharmacol Physiol. 2011;24(4):224-30.

Ayah Shakshuki, BScPharm, MScPharm, is with the College of Pharmacy, Dalhousie University, Halifax, Nova Scotia.

Pollen Yeung, BScPharm, PhD, is with the College of Pharmacy, Dalhousie University, Halifax, Nova Scotia.

Remigius U Agu, BPharm, MPharm, PhD, is with the College of Pharmacy, Dalhousie University, Halifax, Nova Scotia.

Competing interests: None declared.

\section{Address correspondence to:}

Dr Remiguius Agu

College of Pharmacy, Dalhousie University

5968 College Street, PO Box 15000

Halifax NS B3H 4R2

e-mail: Remigius.agu@dal.ca

Funding: This study was funded by the Dalhousie University Pharmacy Endowment Fund. 